\title{
Two-, Three-, and Four-Component Magnetic Multilayer Onion Nanoparticles Based on Iron Oxides and Manganese Oxides
}

\author{
German Salazar-Alvarez, ${ }^{*+}$ Hans Lidbaum, ${ }^{\ddagger}$ Alberto López-Ortega, ${ }^{\S}$ Marta Estrader, ${ }^{\S}$ Klaus Leifer, ${ }^{\ddagger}$
} Jordi Sort, ${ }^{\|, \perp}$ Santiago Suriñach, ${ }^{\perp}$ Maria Dolors Baró, ${ }^{\perp}$ and Josep Nogués $\$$,\|

${ }^{\dagger}$ Department of Materials and Environmental Chemistry, Stockholm University, SE-106 91 Stockholm, Sweden

${ }^{\ddagger}$ Department of Engineering Sciences, Uppsala University, S-75121 Uppsala, Sweden

${ }^{\S} \mathrm{CIN} 2$ (ICN-CSIC) and Universitat Autònoma de Barcelona, Catalan Institute of Nanotechnology (ICN), Campus de la UAB, 08193 Bellaterra (Barcelona), Spain

" Institució Catalana de Recerca i Estudis Avançats (ICREA), Barcelona, Spain

${ }^{\perp}$ Departament de Física, Universitat Autònoma de Barcelona, E-08193 Bellaterra, Spain

Supporting Information

ABSTRACT: Magnetic multilayered, onion-like, heterostructured nanoparticles are interesting model systems for studying magnetic exchange coupling phenomena. In this work, we synthesized heterostructured magnetic nanoparticles composed of two, three, or four components using iron oxide seeds for the subsequent deposition of manganese oxide. The $\mathrm{MnO}$ layer was allowed either to passivate fully in air to form an outer layer of $\mathrm{Mn}_{3} \mathrm{O}_{4}$ or to oxidize partially to form $\mathrm{MnO} \mid \mathrm{Mn}_{3} \mathrm{O}_{4}$ double layers. Through control of the degree of passivation of the seeds, particles with up to four different magnetic layers can be obtained (i.e., $\mathrm{FeO}\left|\mathrm{Fe}_{3} \mathrm{O}_{4}\right| \mathrm{MnO} \mid \mathrm{Mn}_{3} \mathrm{O}_{4}$ ). Magnetic characterization of the samples confirmed the presence of the different magnetic layers.

Tagnetic nanoparticles are very attractive for their novel 1 fundamental properties and numerous current and potential applications. ${ }^{1-3}$ The advances in chemical methods of synthesis have allowed the production of relatively large amounts of narrowly size-distributed nanoparticles with a broad range of compositions and morphologies. ${ }^{4-7}$ Recently, besides singlecomponent nanoparticles, the interest in two-component nanoparticles has steadily increased because of the appealing novel properties and promising applications arising from the simple combination of properties of their constituents or the interaction between them (e.g., see refs 8 and 9 and references therein). Since the report on the use of exchange bias to overcome the superparamagnetic limit, ${ }^{10}$ the number of reports on bimagnetic core-shell (CS) configurations has increased considerably. ${ }^{11}$ At present there are still just a few examples of heterostructured CS systems with distinct chemical compositions, such as $\mathrm{M1Fe}_{2} \mathrm{O}_{4}$ $\mathrm{M} 2 \mathrm{Fe}_{2} \mathrm{O}_{4}(\mathrm{M} 1, \mathrm{M} 2=\mathrm{Mn}, \mathrm{Fe}, \mathrm{Co}, \mathrm{Zn}),{ }^{3,12} \mathrm{FeO} \mid \mathrm{CoFe}_{2} \mathrm{O}_{4}{ }^{13}$ $\mathrm{FePt}\left|\mathrm{MnO},{ }^{14} \mathrm{CoFe}_{2} \mathrm{O}_{4}\right| \mathrm{MnO},{ }^{15}$ and $\mathrm{FePt} \mid \mathrm{M}_{x} \mathrm{Fe}_{3-x} \mathrm{O}_{4}(\mathrm{M}=\mathrm{Fe}$, Co). ${ }^{6,17}$ Nevertheless, reports on more complex multicomponent onion-like magnetic nanoparticles are very scarce. ${ }^{18}$

In this communication, we report the synthesis and microscopic and magnetic characterization of onion-like magnetic nanoparticles with two, three, or four components based on the antiferromagnets (AFMs) $\mathrm{FeO}$ and $\mathrm{MnO}$ and ferrimagnets

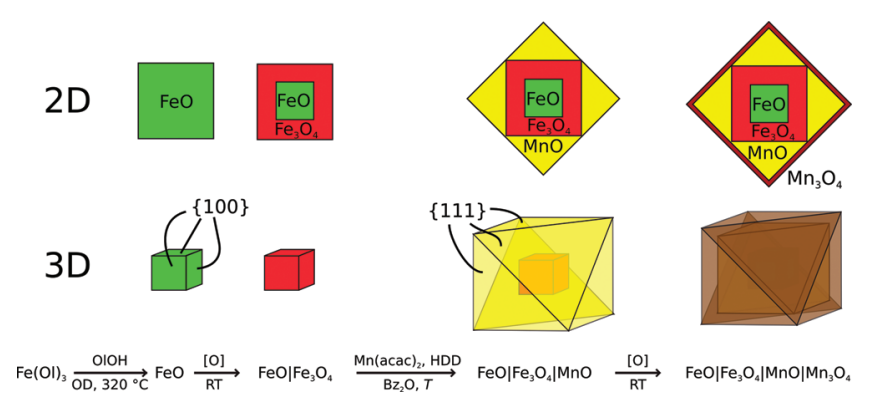

Figure 1. Schematic 2D projections (top) and 3D representations (middle) and the corresponding chemical path of the formation of multicomponent onion nanoparticles (bottom).

(FiMs) $\mathrm{Fe}_{3} \mathrm{O}_{4}$ and $\mathrm{Mn}_{3} \mathrm{O}_{4}$. The multicomponent nanoparticles were fabricated by the heterogeneous growth of manganese oxide shells on iron oxide cores using the latter as seeds, as depicted schematically in Figure 1.

The shape, size, and composition of the initial CS iron oxide nanoparticle seeds were controlled by adjusting the surfactant to precursor ratio, heating rate, and stirring during the reaction. ${ }^{7,19-24}$ The particles were truncated nanocubes with an edge length $(l)$ of $11 \pm 1 \mathrm{~nm}$ consisting of a more electron dense inner core with a size of $\sim 5 \mathrm{~nm}$ and a less electron dense edge of $\sim 3 \mathrm{~nm}$. ${ }^{24}$ Phase analysis of the X-ray diffraction (XRD) measurements suggested two components that could be associated with either $\mathrm{Fe}_{3} \mathrm{O}_{4}$ or $\gamma$ $\mathrm{Fe}_{2} \mathrm{O}_{3}$ and $\mathrm{FeO} .{ }^{24}$ Quantitative analysis of the $\mathrm{Fe} \mathrm{L}_{3} / \mathrm{L}_{2}$ integrated intensity ratio obtained by electron energy loss spectroscopy (EELS) resulted in a ratio of 4.9, indicating that the CS particles had an average composition between $\mathrm{FeO}$ and $\mathrm{Fe}_{3} \mathrm{O}_{4}{ }^{24,25}$ The passivation of the surface layer indicates that the original particles were composed of $\mathrm{FeO}$, which upon exposure to air oxidized to $\mathrm{Fe}_{3} \mathrm{O}_{4}$, in agreement with previous reports (although the presence of $\gamma-\mathrm{Fe}_{2} \mathrm{O}_{3}$ as a result of lattice strains cannot be completely ruled out). ${ }^{26-28}$

The iron oxide CS nanoparticles were used as seeds for the heterogeneous growth of manganese oxide. ${ }^{24}$ Figure 2 a shows

Received: June 30, 2011

Published: October 05, 2011 


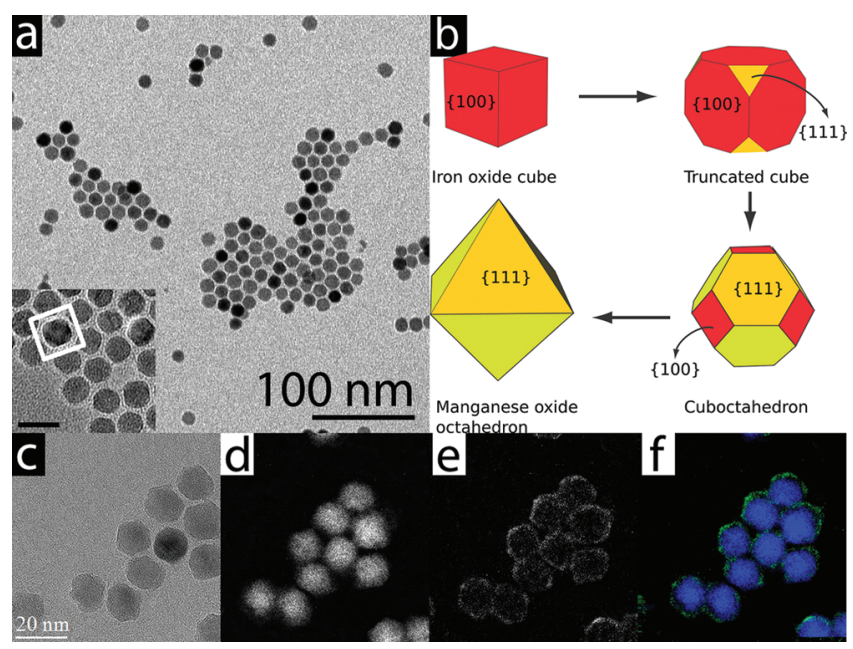

Figure 2. TEM images of the three-component $\mathrm{FeO}\left|\mathrm{Fe}_{3} \mathrm{O}_{4}\right| \mathrm{Mn}_{3} \mathrm{O}_{4}$, onion nanoparticles. (a) Bright-field TEM image of the particles forming hexagonal arrays. In the inset, the marked particle is an octahedral particle with a cubic core, and the scale bar represents $20 \mathrm{~nm}$. (b) Schematic representation of the composition of the particle highlighted in the inset of (a) and a cartoon showing how the CS seed becomes progressively coated with a manganese oxide layer to form an octahedral particle. (c) Bright-field TEM image of the three-component nanoparticles. $(\mathrm{d}-\mathrm{e})$ Corresponding EFTEM micrographs acquired at the $(\mathrm{d})$ iron and (e) manganese $\mathrm{L}_{3}$ edges. (f) Overlay map showing the distribution of iron and manganese in the particles.

bright-field transmission electron microscopy (TEM) micrographs for three-component onion nanoparticles. Remarkably, unlike the seeds with cubic morphology, these particles are larger and seem to have lost the corners to form, probably, cuboctahedrons or truncated octahedrons. Moreover, the self-assembly of the onion nanoparticles leads to the formation of hexagonal arrays, in contrast to the square arrays formed by the seeds. 6,24 The inset of Figure 2 a shows a cuboctahedron with an edge length $l_{\text {oh }}$ of $\sim 14 \mathrm{~nm}$, indicating that it practically embeds a cubic particle with an edge length of $\sim 11 \mathrm{~nm}$. The formation of the cuboctahedrons (or truncated octahedrons) instead of cubes must arise from an increasing surface chemical potential of the $\{111\}$ faces relative to the $\{100\}$ faces. ${ }^{29}$ Indeed, it has been shown that $\mathrm{MnO}$ nanoparticles tend to crystallize in the form of octahedrons with $\{111\}$ faces. ${ }^{5,30-33}$ It is expected that upon exposure to air, the manganese monoxide should oxidize to a higher oxide, i.e., $\mathrm{Mn}_{3} \mathrm{O}_{4}$ ( or $\gamma-\mathrm{Mn}_{2} \mathrm{O}_{3}{ }^{34}$ ), in a similar fashion to the $\mathrm{MnO} \mid \mathrm{Mn}_{3} \mathrm{O}_{4}$ system. ${ }^{34-36}$ On the basis of the $\mathrm{Mn} \mathrm{L}_{3} / \mathrm{L}_{2}$ ratio and the characteristic shape of the $\mathrm{O} \mathrm{K}$ absorption edge ${ }^{37}$ from the corresponding EEL spectra, ${ }^{24}$ the composition of the manganese oxide layer was estimated to be $\mathrm{Mn}_{3} \mathrm{O}_{4}$. The $2-3 \mathrm{~nm}$ thick manganese outer shell was confirmed by electron-filtered TEM (EFTEM) images taken at the $\mathrm{Fe}$ and $\mathrm{Mn} \mathrm{L}_{3}$ edges (Figure $2 \mathrm{~d}-\mathrm{f}$ ). The growth of manganese oxide on the surface of the two-component seeds renders three-component onion nanoparticles with composition $\mathrm{FeO}\left|\mathrm{Fe}_{3} \mathrm{O}_{4}\right| \mathrm{MnO}$, which passivate toward $\mathrm{FeO}\left|\mathrm{Fe}_{3} \mathrm{O}_{4}\right| \mathrm{Mn}_{3} \mathrm{O}_{4}$. XRD results are consistent with this structure. ${ }^{24}$ The synthesis relies in air oxidation of some of the components. Previous reports have shown that the composition thus attained can be stable for months and even be size-dependent. 34,38,39

Thicker manganese oxide layers $(>20 \mathrm{~nm})$ can be grown on the CS seeds using higher decomposition temperatures than in

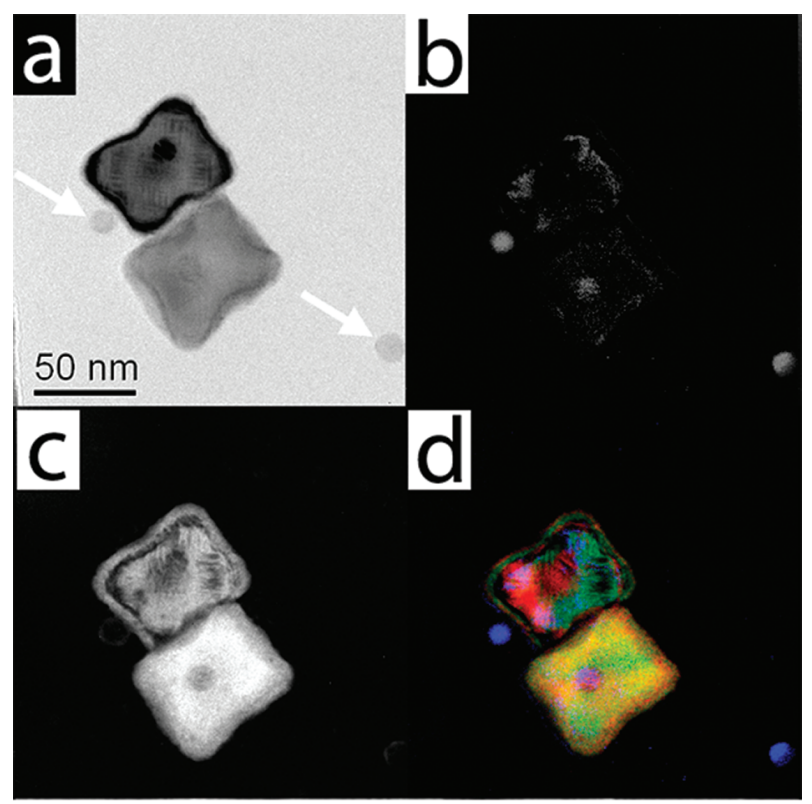

Figure 3. (a) Bright-field TEM image of the four-component $\mathrm{FeO}$ $\mathrm{Fe}_{3} \mathrm{O}_{4}|\mathrm{MnO}| \mathrm{Mn}_{3} \mathrm{O}_{4}$ onion nanoparticles. (b-d) EFTEM micrographs corresponding to (b) iron and (c) manganese and (d) an overlay map showing the distribution of cations in the particles. The arrows in (a) indicate the position of excess two-component CS seeds. The dark inner corona in (c) and (d) is due to diffraction contrast.

the three-component case (see Figure 3). ${ }^{35}$ The manganesecontaining layer was confirmed by EFTEM images taken at the $\mathrm{Fe}$ and $\mathrm{Mn} \mathrm{L}_{3}$ edges (Figure $3 \mathrm{~b}-\mathrm{d}$ ). On the basis of the characteristics of the $\mathrm{MnO} \mid \mathrm{Mn}_{3} \mathrm{O}_{4}$ system, ${ }^{35}$ these particles are expected to be formed from four components, i.e., $\mathrm{FeO}\left|\mathrm{Fe}_{3} \mathrm{O}_{4}\right|$ $\mathrm{MnO} \mid \mathrm{Mn}_{3} \mathrm{O}_{4}$. The presence of both $\mathrm{MnO}$ and $\mathrm{Mn}_{3} \mathrm{O}_{4}$ was determined from magnetization data, as discussed below. A proper differentiation between the different manganese oxides using the XRD and EEL spectra was not possible, as $\mathrm{MnO}$ dominates the signal because of its large volume fraction. ${ }^{24}$ These nanoparticles present a slightly concave geometry, reminiscent of a tetracube. Hofmann et al. ${ }^{40}$ argued that the formation of this type of concave geometry is due to the presence of water during the reaction, which induces some etching of defective areas on the $\{100\}$ faces. Water then helps solubilize some metal (oxy)hydroxide, which recrystallizes on the edges and along the corners according to the Berg effect. ${ }^{41}$

The final size and shape of the three-component nanoparticles, $\mathrm{FeO}\left|\mathrm{Fe}_{3} \mathrm{O}_{4}\right| \mathrm{Mn}_{3} \mathrm{O}_{4}$, is likely to depend on three interrelated mechanisms: (i) seeded growth, which can be discussed in the framework of the Gibbs-Thomson effect and is influenced mainly by the size and curvature of the seeds $\left(\mathrm{FeO} \mid \mathrm{Fe}_{3} \mathrm{O}_{4}\right)$ and the monomer concentration; ${ }^{42}$ (ii) the formation of a heterogeneous layer $(\mathrm{MnO})$ on the initial seeds as manganese oxide is deposited on iron oxide, thereby creating an interface, which can be understood as the spherical case of the Frank-van der Merwe (FM) or Volmer-Weber (VW) regimes ${ }^{43}$ and is affected mostly by the difference in surface energy, lattice mismatch, and degree of supersaturation of the monomer; ${ }^{44}$ and finally (iii) the growth rates of the different crystal faces of the manganese oxide layer, which are likely to be dependent on the type and concentration of surfactant and the initial shape of the seeding particle according to the Wulff-Gibbs criteria of equilibrium. ${ }^{29}$ The use of faceted seeds 

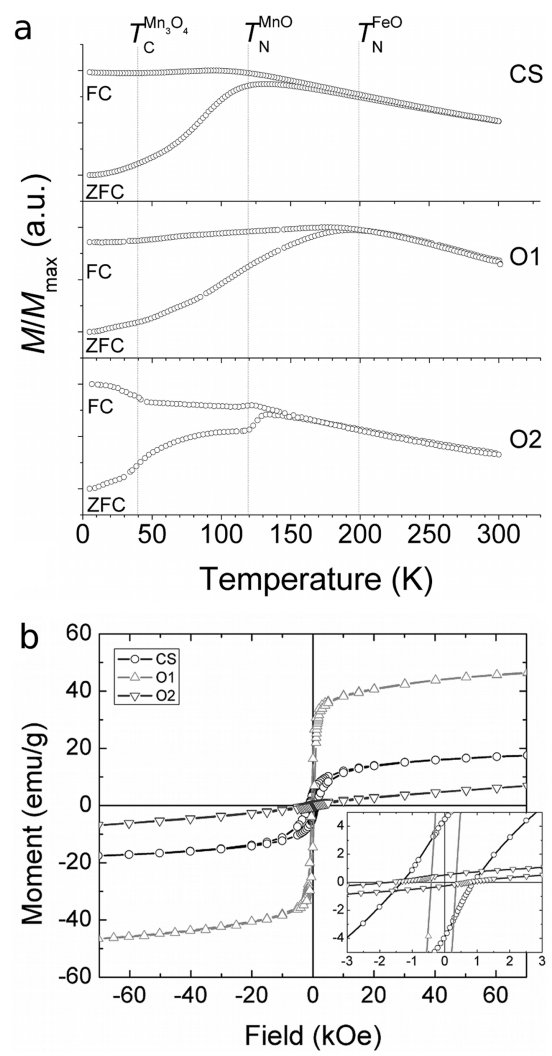

Figure 4. (a) Temperature dependence of the magnetization for the two- (CS), three- (O1), and four-component (O2) onion nanoparticle systems. The measurements were carried out using an applied field $H_{\text {app }}=50$ Oe. The vertical lines indicate the transition temperatures for some of the components. (b) Hysteresis loops at $T=10 \mathrm{~K}$ for samples CS $(O)$, O1 $(\triangle)$, and $\mathrm{O} 2(\nabla)$ cooled from $300 \mathrm{~K}$ under a static field $H_{\mathrm{FC}}=50 \mathrm{kOe}$. The inset shows a magnified view of the central portion of the loops.

serves a twofold purpose: First, it delays the deposition of manganese oxide monomer, which preserves the very narrow size distribution of the seeds. ${ }^{8,29}$ This becomes more apparent upon comparison of the particles shown in Figure 2a with those prepared without the seeds (see ref 35). Second, the morphology of the particles (i.e., truncated cubes) provides well-defined high-energy $\{111\}$ corners where the manganese oxide can be deposited (see Figure $2 b)$. Hence, as the manganese oxide monomer is deposited on the truncated high-energy $\{111\}$ corners of the iron oxide, these grow and the $\{100\}$ planes dissolve to produce a cuboctahedron or truncated octahedron, as illustrated by the cartoon in Figure $2 b$. For the growth of a continuous coating on the seeds, both the outermost layer (mainly $\mathrm{Fe}_{3} \mathrm{O}_{4}$ ) and the developing shell (most probably $\mathrm{MnO}$ ) must accommodate a relatively large lattice mismatch of $\sim 5 \%$. The simplest way to do this is by creating a graded defective interface that is rich in iron and poor in manganese (i.e., $\mathrm{Mn}_{x} \mathrm{Fe}_{3-x} \mathrm{O}_{4}$ ) and enriched toward $\mathrm{MnO}$ at the outermost layer with a low manganese occupancy (i.e., $\mathrm{Mn}_{1-x} \mathrm{O}$ ). The formation of such a defective structure then facilitates its oxidation toward a distorted $\mathrm{Mn}_{3} \mathrm{O}_{4}$ to release further the internal stresses, similar to the $\mathrm{MnO} \mid \mathrm{Mn}_{3} \mathrm{O}_{4}$ system. ${ }^{34-36}$ The formation of the larger four-component nanoparticles proceeds likewise using higher decomposition temperatures. ${ }^{24}$

Figure $4 \mathrm{a}$ shows the field-cooled (FC) and zero-fieldcooled (ZFC) magnetization measurements carried out on the two-component $\mathrm{CS} \mathrm{FeO} \mid \mathrm{Fe}_{3} \mathrm{O}_{4}$ seeds, the three-component $\mathrm{FeO}\left|\mathrm{Fe}_{3} \mathrm{O}_{4}\right| \mathrm{Mn}_{3} \mathrm{O}_{4}$ onion nanoparticles, and the fourcomponent $\mathrm{FeO}\left|\mathrm{Fe}_{3} \mathrm{O}_{4}\right| \mathrm{MnO} \mid \mathrm{Mn}_{3} \mathrm{O}_{4}$ onion particles. As can be seen in the figure, the initial seeds present a blocking temperature $\left(T_{\mathrm{B}}\right)$ of $\sim 120 \mathrm{~K}$, well below the transition temperature of bulk $\mathrm{FeO}\left(T_{\mathrm{N}}=198 \mathrm{~K}\right)$. Notably, although exchange coupling between the AFM core and the FiM shell should bring the blocking temperature of the nanoparticle toward the Neel temperature $\left(T_{\mathrm{N}}\right)$ of the AFM, ${ }^{10}$ this effect depends strongly on the size and anisotropy of the AFM counterpart. $^{45}$ Surprisingly, adding a $2-3 \mathrm{~nm}$ thick layer of $\mathrm{Mn}_{3} \mathrm{O}_{4}$ (with $T_{\mathrm{C}} \approx 43 \mathrm{~K}^{46}$ ) to these cubes results in an increase in $T_{\mathrm{B}}$ toward $\sim 200 \mathrm{~K}$. This effect could have various origins: (a) There is some limited intermixing at the interface of the components (the first nanometer layer), as shown by the EFTEM images, which results in a larger effective volume of the FiM component. This is in agreement with our work on smaller particles. ${ }^{47}$ (b) The growth of the manganese layer on the surface of the cubic seeds proceeds preferentially by growth of the $\{111\}$ faces. This directional growth creates more facets than for a cubic morphology, which can be seen as an effective rounding of the particles, leading to an increase in the effective surface anisotropy and hence $T_{\mathrm{B}}{ }^{7}$ The absence of a clear transition for the $\mathrm{Mn}_{3} \mathrm{O}_{4}$ (except a small shoulder in the $\mathrm{ZFC}$ branch of the magnetization) implies strong exchange coupling between the $\mathrm{Fe}_{3} \mathrm{O}_{4}$ and $\mathrm{Mn}_{3} \mathrm{O}_{4}$ components. Lastly, the fourcomponent $\mathrm{FeO}\left|\mathrm{Fe}_{3} \mathrm{O}_{4}\right| \mathrm{MnO} \mid \mathrm{Mn}_{3} \mathrm{O}_{4}$ onion nanoparticles display several transitions, with those related to the Néel and Curie transitions of $\mathrm{MnO}$ and $\mathrm{Mn}_{3} \mathrm{O}_{4}$ components, respectively, dominating the signal. A shoulder corresponding to the $T_{\mathrm{B}}$ of the $\mathrm{FeO} \mid \mathrm{Fe}_{3} \mathrm{O}_{4}$ cores can also be observed at $\sim 70 \mathrm{~K}$ in the $\mathrm{ZFC}$ branch of the magnetization. Moreover, the presence of loop shifts in the hysteresis (Figure 4b), i.e., exchange bias, ${ }^{11}$ suggests the presence of AFM layers coupled to FiM layers in the particles, as designed. Figure $4 \mathrm{~b}$ shows the hysteresis loops of the samples measured at $T=10 \mathrm{~K}$ after cooling under a field $H_{\mathrm{FC}}=50 \mathrm{kOe}$. All of the samples show a loop shift $\left(H_{\mathrm{E}}\right)$, with the largest being that for the four-component nanoparticle system (sample O2). The temperature dependences of the coercivity and loop shift of the three different samples are shown in Figure S4 in the Supporting Information. As expected from its components, the coercivity and loop shift of the CS sample decay slowly toward the blocking temperature of the system. In the case of the $\mathrm{Mn}_{3} \mathrm{O}_{4}$-containing samples, the coercivity and loop shift decay rapidly near the Curie temperature $\left(T_{\mathrm{C}}^{\mathrm{Mn}_{3} \mathrm{O}_{4}} \approx 40 \mathrm{~K}\right)$. The effect is more pronounced in the four-component nanoparticle system, where most of the magnetic volume corresponds to the AFM MnO. Thus, the coercivity decays nearly $90 \%$, although there is a remanent component that disappears near the Néel temperature $\left(T_{\mathrm{N}}^{\mathrm{MnO}}\right.$ $\approx 120 \mathrm{~K})$.

Taking advantage of the surface oxidation of $\mathrm{FeO}$ and $\mathrm{MnO}$ allows nanoparticles with various compositions and number of components to be produced: (i) two-component $\mathrm{FeO} \mid \mathrm{Fe}_{3} \mathrm{O}_{4}$ nanoparticles can be synthesized directly, and (ii) three-component $\mathrm{FeO}\left|\mathrm{Fe}_{3} \mathrm{O}_{4}\right| \mathrm{Mn}_{3} \mathrm{O}_{4}$ nanoparticles or (iii) four-component $\mathrm{FeO}\left|\mathrm{Fe}_{3} \mathrm{O}_{4}\right| \mathrm{MnO} \mid \mathrm{Mn}_{3} \mathrm{O}_{4}$ nanoparticles can be obtained from CS $\mathrm{FeO} \mid \mathrm{Fe}_{3} \mathrm{O}_{4}$ seeds by growing a single $\mathrm{Mn}_{3} \mathrm{O}_{4}$ layer or a $\mathrm{MnO} \mid \mathrm{Mn}_{3} \mathrm{O}_{4}$ double layer, respectively. Magnetic measurements suggest that the interfacial effects dominate in the threecomponent particles, whereas $\mathrm{MnO}$ dominates in the fourcomponent particles. 


\section{ASSOCIATED CONTENT}

Supporting Information. Experimental details and additional results. This material is available free of charge via the Internet at http://pubs.acs.org.

\section{AUTHOR INFORMATION}

\section{Corresponding Author}

german@mmk.su.se

\section{ACKNOWLEDGMENT}

This work was supported by the Spanish MICINN (MAT200801939-E, MAT2010-20616-C02, CSD2006-00012 Consolider Ingenio 2010) and the Catalan DGR (2009-SGR-1292). The authors thank the Serveis Cientfico-tècnics de la UAB. G.S.-A. thanks the Wallenberg Wood Science Center for partial financial support. M.D. B. was partially supported by an ICREA ACADEMIA Award.

\section{REFERENCES}

(1) Laurent, S.; Forge, D.; Port, M.; Roch, A.; Robic, C.; Elst, L. V.; Muller, R. N. Chem. Rev. 2008, 108, 2064.

(2) Härmä, H.; Laakso, S.; Pihlasalo, S.; Hänninen, P.; Faure, B.; Rana, S.; Bergström, L. Nanoscale 2010, 2, 69.

(3) Lee, J.-H.; Jang, J.-T.; Choi, J.-S.; Moon, S.-H.; Noh, S.-H.; Kim, J.-W.; Kim, J.-G.; Kim, I.-S.; Park, K.-I.; Cheon, J. Nat. Nanotechnol. 2011, 6, 418.

(4) Cheon, J.; Kang, N.; Lee, S.; Lee, J.; Yoon, J.; Oh, S. J. Am. Chem. Soc. 2004, 126, 1950.

(5) Park, J.; An, K.; Hwang, Y.; Park, J.-G.; Noh, H.-J.; Kim, J.-Y.; Park, J.-H.; Hwang, N.-M.; Hyeon, T. Nat. Mater. 2004, 3, 891.

(6) Disch, S.; Wetterskog, E.; Hermann, R.; Salazar-Alvarez, G.; Busch, P.; Bergström, L.; Brückel, T.; Kamali, S. Nano Lett. 2011, 11, 1651.

(7) Salazar-Alvarez, G.; Qin, J.; Šepelák, V.; Bergman, I.; Vasilakakis, I.; Trohidou, K.; Ardisson, J.; Macedo, W.; Mikhaylova, M.; Muhammed, M.; Baró, M.; Nogués, J. J. Am. Chem. Soc. 2008, 130, 13234.

(8) Costi, R.; Saunders, A.; Banin, U. Angew. Chem., Int. Ed. 2010, 49, 4878.

(9) Carbone, L.; Cozzoli, P. D. Nano Today 2010, 5, 449.

(10) Skumryev, V.; Stoyanov, S.; Zhang, Y.; Hadjipanayis, G.; Givord, D.; Nogués, J. Nature 2003, 423, 850.

(11) Nogués, J.; Sort, J.; Langlais, V.; Skumryev, V.; Suriñach, S.; Muñoz, J. S.; Baró, M. D. Phys. Rep. 2005, 422, 65.

(12) Masala, O.; Hoffman, D.; Sundaram, N.; Page, K.; Proffen, T.; Lawes, G.; Seshadri, R. Solid State Sci. 2006, 8, 1015.

(13) Bodnarchuk, M. I.; Kovalenko, M. V.; Groiss, H.; Resel, R.; Reissner, M.; Hesser, G.; Lechner, R. T.; Steiner, W.; Schäffler, F.; Heiss, W. Small 2009, 5, 2247.

(14) Kang, S.; Miao, G. X.; Shi, S.; Jia, Z.; Nikles, D. E.; Harrell, J. W. J. Am. Chem. Soc. 2006, 128, 1042.

(15) Masala, O.; Seshadri, R. J. Am. Chem. Soc. 2005, 127, 9354.

(16) Zeng, H.; Li, J.; Wang, Z. L.; Liu, J. P.; Sun, S. Nano Lett. 2004, 4, 187.

(17) Zeng, H.; Sun, S.; Li, J.; Wang, Z. L.; Liu, J. P. Appl. Phys. Lett. 2004, 85, 792 .

(18) Catala, L.; Brinzei, D.; Prado, Y.; Gloter, A.; Stéphan, O.; Rogez, G.; Mallah, T. Angew. Chem., Int. Ed. 2009, 48, 183.

(19) Park, J.; Lee, E.; Hwang, N.; Kang, M.; Kim, S.; Hwang, Y.; Park, J.; Noh, H.; Kim, J.; Park, J.; Hyeon, T. Angew. Chem., Int. Ed. 2005, 44, 2872.

(20) Kovalenko, M. V.; Bodnarchuk, M. I.; Lechner, R. T.; Hesser, G.; Schäffler, F.; Heiss, W. J. Am. Chem. Soc. 2007, 129, 6352.

(21) Ahniyaz, A.; Sakamoto, Y.; Bergström, L. Proc. Natl. Acad. Sci. U.S.A. 2007, 104, 17570 .
(22) Shavel, A.; Rodríguez-González, B.; Spasova, M.; Farle, M.; Liz-Marzán, L. M. Adv. Funct. Mater. 2007, 17, 3870.

(23) Gao, G.; Liu, X.; Shi, R.; Zhou, K.; Shi, Y.; Ma, R.; TakayamaMuromachi, E.; Qiu, G. Cryst. Growth Des. 2010, 10, 2888.

(24) see the Supporting Information for more details.

(25) Colliex, C.; Manoubi, T.; Ortiz, C. Phys. Rev. B 1991, 44, 11402.

(26) Redl, F.; Black, C.; Papaefthymiou, G.; Sandstrom, R.; Yin, M.; Zeng, H.; Murray, C.; O’Brien, S. J. Am. Chem. Soc. 2004, 126, 14583.

(27) Chen, C.; Chiang, R.; Lai, H.; Lin, C. J. Phys. Chem. C 2010, 114,4258 .

(28) Hai, H. T.; Yang, H. T.; Kura, H.; Hasegawa, D.; Ogata, Y.; Takahashi, M.; Ogawa, T. J. Colloid Interface Sci. 2010, 346, 37.

(29) Sugimoto, T. Adv. Colloid Interface Sci. 1987, 28, 65.

(30) Djerdj, I.; Arčon, D.; Jagličić, Z.; Niederberger, M. J. Phys. Chem. C 2007, 111, 3614.

(31) Park, J.; Kang, E.; Bae, C. J.; Park, J.-G.; Noh, H.-J.; Kim, J.-Y.; Park, J.-H.; Park, H. M.; Hyeon, T. J. Phys. Chem. B 2004, 108, 13594.

(32) Seo, W.; Jo, H.; Lee, K.; Kim, B.; Oh, S.; Park, J. Angew. Chem., Int. Ed. 2004, 43, 1115.

(33) Li, Q.; Wang, J.; He, Y.; Liu, W.; Qiu, X. Cryst. Growth Des. 2009, 9, 3100 .

(34) López-Ortega, A.; Tobia, D.; Winkler, E.; Golosovsky, I. V.; Salazar-Alvarez, G.; Estradé, S.; Estrader, M.; Sort, J.; González, M. A.; Suriñach, S.; Arbiol, J.; Peiró, F.; Zysler, R. D.; Baró, M. D.; Nogués, J. J. Am. Chem. Soc. 2010, 132, 9398.

(35) Salazar-Alvarez, G.; Sort, J.; Suriñach, S.; Baró, M. D.; Nogués, J. J. Am. Chem. Soc. 2007, 129, 9102.

(36) Golosovsky, I.; Salazar-Alvarez, G.; Lopez-Ortega, A.; González, M.; Sort, J.; Estrader, M.; Suriñach, S.; Baró, M.; Nogués, J. Phys. Rev. Lett. 2009, 102, No. 247201.

(37) Paterson, J. H.; Krivanek, O. L. Ultramicroscopy 1990, 32, 319.

(38) Santoyo Salazar, J.; Perez, L.; de Abril, O.; Truong Phuoc, L.; Ihiawakrim, D.; Vazquez, M.; Greneche, J.-M.; Begin-Colin, S.; Pourroy, G. Chem. Mater. 2011, 23, 1379.

(39) Spasova, M.; Wiedwald, U.; Farle, M.; Radetic, T.; Dahmen, U.; Hilgendorff, M.; Giersig, M. J. Magn. Magn. Mater. 2004, 272-276, 1508.

(40) Hofmann, C.; Rusakova, I.; Ould-Ely, T.; Prieto-Centurión, D.; Hartman, K. B.; Kelly, A. T.; Lüttge, A.; Whitmire, K. H. Adv. Funct. Mater. 2008, 18, 1661.

(41) Sunagawa, I. Crystals: Growth, Morphology, and Perfection; Cambridge University Press: Cambridge, U.K., 2005.

(42) In the case of diffusion-controlled growth, the growth rate is $\mathrm{d} r /$ $\mathrm{d} t=(K / r)\left(1 / r^{*}-1 / r\right)$, i.e., a function of the monomer diffusion constant $K$, the radius of critical solubility $r^{*}$, and the particle radius $r$ (see ref 29).

(43) Bauer, E.; van der Merwe, J. H. Phys. Rev. B 1986, 33, 3657.

(44) The change in the surface energy is given by $\Delta \gamma=\gamma_{\mathrm{S}}-\gamma_{\mathrm{C}}+$ $\gamma_{\mathrm{CS}}$, where $\gamma_{\mathrm{C}}$ is the surface energy of the core, $\gamma_{\mathrm{S}}$ is the surface energy of the component to be deposited (the shell), and $\gamma_{\mathrm{CS}}$ the interfacial energy $\left(\gamma_{\mathrm{CS}}<0\right.$ for small lattice mismatch and strong CS adhesion). When $\Delta \gamma<0$, the deposition occurs homogeneously over the seed (FM regime), whereas in the opposite case with $\Delta \gamma<0$, the deposition is not homogeneous, and the component instead grows as islands (VW regime). ${ }^{43}$

(45) Nogués, J.; Skumryev, V.; Sort, J.; Stoyanov, S.; Givord, D. Phys. Rev. Lett. 2006, 97, No. 157203.

(46) Guillou, F.; Thota, S.; Prellier, W.; Kumar, J.; Hardy, V. Phys. Rev. B 2011, 83, No. 094423.

(47) Estradé, S.; Yedra, L.; López-Ortega, A.; Estrader, M.; SalazarAlvarez, G.; Baró, M.; Nogués, J.; Peiró, F. Micron [Online early access]. DOI: 10.1016/j.micron.2011.04.002. Published Online: April 16, 2011. 